\title{
ASPECTOS FILOSÓFICOS NA LICENCIATURA EM EDUCAÇÃO DO CAMPO
}

\section{PHILOSOPHICAL ISSUES IN DEGREE IN EDUCATION FIELD}

\author{
Wender Faleiro ${ }^{1}$ \\ Magno Nunes Farias ${ }^{2}$
}

\begin{abstract}
Resumo:Na institucionalização da Licenciatura em Educação do Campo se torna fundamental a construção do Projeto Político-Pedagógico (PPP), que é constituído com base em fundamentos filosóficos, que trazem questões sobre como essa instituição reflete e concebe a realidade do campo, bem como concepções dos sujeitos do campo, do território, da educação e dos próprios Educadores do Campo. Sendo assim, o objetivo aqui posto foi resgatar e trazer reflexões sobre esses fundamentos filosóficos do PPP da LEdoC da UFG, a partir de uma Pesquisa Documental, utilizando a Análise de Conteúdo. Nota-se que o PPP desenvolve uma filosofia da Educação do Campo ou filosofia do homem do campo para embasar suas concepções acerca dos processos educativos da LEdoC, concebe uma formação voltada para a realidade concreta do campo brasileiro, frisando a importância da vinculação a cultura e aos modos de vida dos sujeitos. Há, porém, problemáticas, como no processo de construção do documento (que não reflete uma perspectiva coletiva), e a dificuldade de se materializar no mesmo questões que marcam a Educação do Campo de maneira mais radical, como questões relacionadas a reforma agrária e formação de intelectuais com consciência de classe trabalhadora.
\end{abstract}

Palavras-Chave: Filosofia; Educação do Campo; Licenciatura; Projeto político-pedagógico.

\begin{abstract}
The institutionalization degree in Rural Education of these Undergraduate becomes fundamental construction of the Political-Pedagogical Project (PPP), which is made based on philosophical foundations that bring questions about how this institution reflects and sees the reality of the field, as well as conceptions of the subject field, planning, education and Field Educators themselves. So the goal here was put rescue and bring reflections on these philosophical foundations PPP of LEdoC, UFG, from a Document Search using the Content Analysis. Note that the PPP develops a philosophy field of education or field man philosophy to support his views about educational processes LEdoC conceives oriented training to the concrete reality of the Brazilian countryside, stressing the importance of linking culture and the ways of life of the subjects. There is, however, problematic, as in the document the construction process (which does not reflect a collective perspective), and the difficulty to materialize the same issues that make the Field of Education in a more radical way, as issues related to land reform and training intellectuals with working-class consciousness.
\end{abstract}

Keywords: Philosophy; Rural Education; Graduation; political-pedagogical project.

\footnotetext{
${ }^{1}$ Grupo de Estudos, Pesquisa e Extensão em Ensino de Ciências e Formação de Professores - GEPEEC. Professor do Programa de Pós-Graduação em Educação da Universidade Federal de Goiás/Regional Catalão - Campus I. Av. Dr. Lamartine Pinto de Avelar, 1120. Setor Universitário - CEP 75704-020 - Catalão, GO. E-mail: wender.faleiro@gmail.com.

${ }^{2}$ Grupo de Estudos, Pesquisa e Extensão em Ensino de Ciências e Formação de Professores - GEPEEC. Mestrando do Programa de Pós-Graduação em Educação da Universidade Federal de Goiás/Regional Catalão Campus I. Av. Dr. Lamartine Pinto de Avelar, 1120. Setor Universitário - CEP 75704-020 - Catalão, GO.
} 


\section{INTRODUÇÃO}

Um dos processos essenciais para efetivar o acesso à Educação do Campo é a necessidade que se tenha docentes, nas escolas do campo, capazes e empoderados para colocar em prática um fazer pedagógico que realmente esteja afinado com as questões que envolvem os sujeitos do campo. Sendo necessário então políticas que estimulem e tornem possíveis formações em magistério para sujeitos com o potencial de atuar no educar do campo de maneira transformadora. Tendo esse aspecto em vista, se consolidou a proposta de criação das Licenciaturas em Educação do Campo (LEdoC) nas Instituições de Ensino Superior (IES) brasileiras. Para sua consolidação o governo federal do Brasil lança o PROCAMPO (Programa de Apoio à Formação Superior em Licenciatura em Educação do Campo), vinculado ao Ministério da Educação, que apoio a implementação das LEdoC nas instituições, que vem lançando editais para a consolidação das licenciaturas em universidades e institutos brasileiros. Desta forma, já existem 42 cursos instituídos em todo Brasil (Campos, 2015; Molina, 2015).

A Licenciatura está estreitamente vinculada com os Movimentos Sociais do campo que se intensificaram na década de 80, lutando por uma educação no campo e do campo, consolidando o Movimento de Educação do Campo, que busca superar uma educação urbanocentrada (que deslegitima da cultura do campo) e técnica (formação de mão de obra). Assim, a Educação do Campo busca, enquanto prática constituída por estratégias simbólicas de ação, investir no desenvolvimento dos sujeitos subjetivamente de formar a consolidar novas maneiras de olhar as relações dos sujeitos do campo com o mundo social, de formar conscientizadora e crítica (Molina, 2015). Desta forma, objetiva desencadear nos futuros educadores

[...] um nível de conhecimento que não é meramente descritivo, repassador de dados técnicos, mas compreensivo, interpretativo, reflexivo, desmascarador de ilusões e falseamentos que obscureçam as articulações do poder social, vigentes idelogicamente na sociedade (Severino, 2012, p.70).

Assim, a Educação do Campo, em todos níveis da educação, seja formando educandos no Educação Superior ou Básica, busca desenvolver percursos educativos com bases na criticidade, debruçando-se principalmente nas realidades dos povos do campo, superando concepções marginalizadoras sobre seus modos de vida, e deixando postas as contradições socioeconômicas que vem ameaçando suas existências no território rural. Tem a finalidade desconstruir estruturas de desigualdade, tendo em vista que a educação tem o papel fundamental nas relações sociais e históricas, que estrutura as relações em sociedade (Caldart, 
2008; Severino, 2012). Nessa perspectiva contra-hegemônica se propõe a traçar objetivos a partir das atividades concretas dos sujeitos do campo e suas necessidades sociais como classe trabalhadora, superando uma educação com "ênfase depositada na noção de preparação para um futuro remoto e pela transformação do trabalho, tanto do professor como do aluno, em algo mecânica e servil” (Dewey, 2007, p.27).

A Educação se consolidando como prática sociopolítica, produzindo conscientização das subjetivas dos educandos que "atua sobre as representações, conceitos e valores das pessoas, mediante a comunicação intersubjetiva" (Severino, 2012, p. 72). Esse processo de conscientização historicamente e contemporaneamente tem sido articulado a partir de relações de poder gerenciadas pelas relações ideológicas e econômicas, que vem negando a existência dos povos do campo, a partir de processos de exclusão. Assim, a educação acabou contribuindo na reprodução de conteúdos que legitimassem as ideologias e as relações de produção dominantes, ou seja, ideias que concebem o homem do campo com inexistente e com valores culturais desqualificados, e relações de produção que os sujeitasse a modelos de produção capitalista (Agronegócio), os submetendo a uma educação para formação de mão de obra.

Além disso, essas concepções também residem na Filosofia Dualista, que legitimam divisões de classe, e segregam grupos sociais entre ricos e pobres, desencadeando assim dualismos educacionais históricos e contemporâneos. A existência dessas distinções socialmente entre sujeitos que possuem capacidades para o mundo racional e os sujeitos capacitados apenas para o trabalho, reverberam nos sistemas educacionais, que acaba reafirmada nas relações de classe separando modelos de educação dos que necessitam do trabalha para sobreviver e dos que não (Dewey, 2007). Assim, esses processos

[...]provocaram a divisão entre uma educação liberal [no sentido de livre, que não objetiva educação profissional], relacionada com a auto-suficiente vida de lazer, devotada a conhecer por conhecer, e o treinamento útil, prático para as ocupações mecânicas, destituídos de conteúdo intelectual e estético (Dewey, 2007, p.45).

Dentro desse contexto, uma das populações fortemente atingidas por esses processos são as populações do campo. O que marca principalmente esse processo é modelo de Educação Rural (oferecido para a população do campo principalmente nas décadas de 50, 60 e 70), que elaborou diversos projetos educacionais para campo, porém esses eram projetos fixos e fechados, inviabilizando qualquer participação dos sujeitos do campo em sua elaboração, sendo uma estratégia paliativa para desvia a atenção das reais necessidades desses povos. Além disso, esses projetos não dialogavam com perspectivas emancipatórias (para uma vida mais digna dos sujeitos, sem relações de opressão econômica, cultural e social), 
pelo contrário, legitimava o modo de produção capitalista, com a finalidade de instituir um processo de instrução e inculcação para a população do campo se tornar mão de obra subordinada ao processo de expansão do capitalismo no campo brasileiro (Calazans et al., 1981). Sendo assim, a Educação do Campo busca superar o modelo de Educação Rural, desenvolvendo um projeto de educação pautado na justiça social e na afirmação dessa classe como sujeitos de direito a uma educação transformadora, crítica e voltado para seus modos de existência, rompendo uma lógica de preparação mecânica para o trabalho.

A Educação do Campo então assenta-se sobre essa base, de produzir movimentos contra-ideológicos confrontando concepções de interesses dominantes, apostando assim em uma educação capaz de transformar as relações sociais dominação e subordinação, nesse sentido concebem o potencial de transformação da Educação em tornar o mundo mais justo (Severino, 2012; Caldart, 2008).

\section{Projeto Político-Pedagógico e a Filosofia da Educação}

Desde a década de 80 o PADES - Programa de Apoio às Instituições de Ensino Superior, vinculado ao Ministério da Educação, coloca a necessidade de se constituir Projetos Políticos-Pedagógicos ${ }^{3}$ (PPP) na educação superior, sendo esse um dos principais documentos relacionado à qualidade da instituição até os dias de hoje (Silva, 2004). O PPP se constrói como um documento capaz de deixar posto

[...] opções, definir intencionalidades e perfis profissionais, decidir sobre os focos decisórios do currículo (objetivos, conteúdo, metodologia, recursos didáticos e avaliação), analisar as condições reais e objetivas de trabalho, otimizar recursos humanos, físicos e financeiros, estabelecer e administrar o tempo para o desenvolvimento das ações, enfim, coordenar os esforços em direção a objetivos e compromissos futuros (Veiga, 2007, p.13)

Deve-se se atentar o PPP é mais que uma formalidade ou um simples agrupamento de planos de ação e atividades, ele deve ser vivenciado e constituído a todo o momento durante os processos educativos da instituição. Tendo sua construção em dois níveis: na organização do ambiente educativo, bem como nas suas relações com os contextos sociais e econômicos. Assim, o PPP é a elaboração do que deve ser lançado futuramente, sendo construído a partir de concepções utópicas, que deve vir a ser possível realizar no futuro, o que está estreitamente ligado com o papel da constituição desse documento com potencialidade de transformações

\footnotetext{
$3 \mathrm{Na}$ época existia uma diversidade de terminologia, bem como atualmente. A Lei de Diretrizes e Bases da Educação (Lei 9.394/96) se refere ao documento como "proposta pedagógica" ou "projeto pedagógico" (Silva, 2004). Além disso, tem outros termos como "projeto político do curso ou institucional". Porém, aqui optou-se por utilizar Projeto Político-Pedagógico, tendo como referência Veiga (2007).
} 
de ordens sociais instituídas. Não se pode esquecer que o projeto é uma construção coletiva e participativo, tendo efeito sobre a construção de atividades dos protagonistas (docentes, discentes, comunidade e técnicos), pois acaba gerando corresponsabilidades educativas para todo os sujeitos que participaram da construção (Veiga, 2007).

No processo de formação de professores o PPP tem como finalidade orientar os processos formativos desses sujeitos, com o objetivo de direciona-lo com base no processo de “ensinar, aprender, pesquisar e avaliar na universidade" (Veiga, 2007, p.96). Além disso, o PPP deve construir esse processo formativo baseado na tríade da pesquisa, ensino e extensão, com pontes entre teoria e prática/formação inicial e continuada, tornando esses processos indissociáveis. Desta forma, o PPP se consolida como instrumento que media o movimento de formação desses sujeitos, nesse sentido esse documento é um rico espaço que se propõe a articular aspectos práticos e teóricos, ou seja, no âmbito do agir e pensar, sobre os tensionamentos que envolvem o processo de formação docente, e nesse movimento ele pode ser gerador de processos reprodutivistas ou instrumento de superação de paradigmas (Fagundes, 2009).

A partir da concepção da necessidade e se construir um PPP com base progressista, que tenha como princípio as práticas sociais e tenha como finalidade solucionar e problematizar as tensões da educação, um dos pressupostos norteadores para sua construção, de acordo com Veiga (1998), devem ser os aspectos filosóficos, sendo esses capazes de olhar para educação como um compromisso político, que é direito da população, que tem como objetivo contribuir para o desenvolvimento de cidadãos participativos no desenvolvimento do país.

Dentro dessas concepções Carvalho (2009) também afirma que é fundamental que o PPP tenha bases filosóficas, pois esses preceitos são essenciais para se delinear de que sujeitos está se falando nesse documento (sujeitos da comunidade e os próprios discentes em formação), bem como as concepções sobre a sociedade em que se vive e os processos de transformação da mesma. Dessa maneira é fundamental que se desenvolva questões de embasamento filosóficos no PPP da LEdoC, ou espera-se que seja desenvolvido, tendo em vista que filosofia se entende como área de conhecimento que se propõe a observar, problematizar, discutir e questionar como a educação do homem é posto dentro das dinâmicas de relação com o mundo (Dewey, 2007).

A Filosofia se torna um sistema fundamental por debruçar-se em refletir sobre problemas, conflitos e dificuldades relacionadas ao fazer humano, ao corpo e alma, as relações da vida social, ao saber e fazer, ao indivíduo e ao coletivo, ou seja, a todos os 
aspectos que tencionam as práticas sociais e desafios relacionados as experiências reais do sujeito em sociedade. Cabe a filosofia refletir sobre as maneiras dos sujeitos agirem sobre o mundo que é sistematizado pela ciência, se caracterizando pela tentativa de acolher os fatos em uma totalidade e assim em um processo continuo não fragmentando, desta forma, torna possível o resgate de fatos isolados para investigar seus sentidos dentro das relações macrossociais (Dewey, 2007).

Teixeira (1971) concebe que a filosofia se configura em uma busca de construir um método que possa problematiza, julgar, desvendar os valores concretos da vida humana, objetivando seu entendimento para uma vida melhor. Não busca por aspectos científicos e verdades, e sim valores, intepretações e sentidos multidimensionais para uma compreensão cada vez mais larga e profunda sobre as relações sociais. $\mathrm{O}$ autor reafirma que esse processo de compreensão da vida e do mundo se dá em uma "todo único", para se debruçar sobre as experiências humanas de maneira mais completa possível, sem fragmentar aspectos humanos. Assim, "a filosofia é a indagação da atitude que devemos tomar diante das incertezas e conflitos da vida [...]. É exatamente porque há dúvidas e incerteza e perplexidades que temos necessidade de uma filosofia" (Ibidem, p.146)

Partindo dessas concepções, a filosofia se debruça nos processos educativos (como o PPP) com a finalidade de refletir como se dá a existência humanas dentro das práticas sociais educacionais, bem como deixar posto as concepções filosóficas sobre o mundo, a vida, a educação e os sujeitos, se denominando assim como a Filosofia da Educação (Severino, 2012). Além disso, a Filosofia da Educação deve ser capaz desenvolver processo reflexivos tensionados de ideologias, gerando conflitos sobre os processos históricos e os movimentos sociais que rodeiam as concepções educativa, tendo um potencial crítico em elaborar contraideologias. Dewey (2007) discorre que a educação e a filosofia estão estreitamente vinculadas, tendo em vista que as problemáticas filosóficas surgem a partir de uma prática social concreta, sendo a educação um campo produtor de diversas questões que problematizam a existência humana de maneira concreta e pragmática. "O ponto de vista educacional habilita a enxergar os problemas filosóficos onde eles surgem e se desenvolvem, onde residem e onde sua aceitação ou rejeição faz diferença na prática” (Ibidem, p.82).

Tendo em vista os diálogos entre educação e filosofia para buscar discutir os problemas da existência humana em seus diversos contextos sociais, sendo a educação um campo onde pode-se compreender o agir da filosofia de maneira pura e intensa. Propomos aqui compreende, com base nessa concepção de filosofia, como os fundamentos filosóficas são postas dentro do PPP, instrumento que materializar e direciona processos educativos, da 
LEdoC da Universidade Federal de Goiás/Regional Catalão (UFG/RC), tendo em vista que a compreensão de como essas questões são postas no documento indica a visão da instituição universitária sobre os processos de formação de Educadores do Campo, e muito além disso, sobre a própria concepção da existência do campo, dos sujeitos que o constituem, seus modos de vida do campo e suas relações com o mundo, na sociedade brasileira especificamente.

Ou seja, busca-se aqui investigar os aspectos filosóficos do PPP, afim de trazer problematizações, arriscando-se em um percurso filosófico de como ocorre a interpretação da existência desses sujeitos do campo, em suas dinâmicas sociais e a própria concepção sobre o que vem a ser um futuro Professor do Campo, e como isso se dá nesse processo de reflexão dessas práticas sociais que estão dentro do processo educativo descrito no PPP da Licenciatura em Educação do Campo da UFG, RC.

\section{METODOLOGIA}

Trata-se de uma pesquisa qualitativa de abordagem documental, que utilizará a análise de conteúdo como estratégia de tratamento dos dados. A pesquisa documental se caracteriza pelo exame de documentos que ainda não receberam uma análise aprofundada, com objetivo de buscar novas interpretações sobre o mesmo. Além disso, os documentos são fontes naturais de informações sobre determinadas concepções, contextos e diversas questões que rodearam o processo de elaboração desse documento. Sendo posta aqui em uma abordagem qualitativa, tendo em vista a necessidade de se elaborar reflexões em níveis não mensuráveis, mas a partir de interpretações subjetivas sobre as concepções filosóficas trazidas nos documentos (GODOY, 1995).

A Análise de Conteúdo se configura como um "conjunto de técnicas de análise das comunicações" (Bardin, 2011, p.37), que possibilita sua aplicabilidade a uma diversidade de discursos, informações ou conteúdos quando o objetivo é compreender esses conteúdos de forma mais aprofundada, superando interpretações imediatas e superficiais. Desta maneira, a análise busca desvendar sentidos e significados que podem estar por trás dos discursos analisados, o pesquisador deve então fazer um esforço duplo, em compreender o sentido da mensagem como um receptor comum, e ir mais além, debruçando-se com um olhar analítico sobre outras significações ou mensagens que estão postas de maneira indireta nesse documento, fazendo assim inferências (Godoy, 1995)

O documento analisado foi o PPP da LEdoC - UFG/RC, com base nas premissas iniciais, de buscar como é posto os fundamentos filosóficos dentre desse documento, e a partir 
de concepções de filosofia elaboradas anteriormente. Propondo assim, traçar um movimento filosófico em problematizar e questionar os próprios elementos filosóficos do PPP, tendo em vista as concepções que perpassam esse documento.

No mês de outubro de 2012, o Departamento de Educação da Regional Catalão (RC), da UFG, propôs a criação do curso de LEdoC em concorrência ao edital PROCAMPO de seleção No 2/2012 - SESU/SETEC/SECADI/MEC. A proposta foi aprovada pelo MEC/SECADI por meio da Portaria n. 72, de 21 de dezembro de 2012 da SECADI e publicado no DOU edição n. 249, de 27 de dezembro de 2012. Assim, o curso de LEdoC foi instituído em 2013 com habilitação em Ciências da Natureza na modalidade presencial em regime de alternância (Tempo Universidade - Tempo Comunidade), tendo como eixo orientador a formação para a docência e a responsabilidade social (Campos, 2015). A primeira turma ingressou em janeiro de 2014, o PPP analisado aqui foi construído nesse mesmo ano.

\section{RESULTADOS E DISCUSSÃO}

Ao analisarmos as bases da construção do PPP da LEdoC da Universidade em questão, que é o Edital PROCAMPO $\mathrm{N}^{\circ}$ 2/2012, verificamos que foi posto como a necessidade de se definir a filosofia do curso, com base principalmente na Política Nacional de Educação do Campo (PRONACAMPO), que se configura uma política com objetivo de oferecer apoio técnico e financeiro para os Estados, Municípios e Distrito Federal para a implementação de políticas para Educação do Campo, objetivando a ampliação do acesso à educação básica e superior da população do campo, com melhorias na infraestrutura, formação continuada e inicial de professores e produção de mateai didáticos (Brasil, 2012).

A construção do PPP a partir de uma ótica inovadora deve ocorrer por meio de rupturas com lógicas instituídas, mas principalmente, teve ser uma construção de base coletiva, repensando as relações de poder, e essencialmente "da periferia para o centro, de baixo para cima" (Veiga, 2007, p.21). Porém, não se identificou uma perspectiva coletiva que embasou a construções do documento em questão, esse aspecto é nebuloso dentro do PPP, não é posto como foi o processo de construção do documento, se teve articulação com os Movimento Sociais do Campo, se teve estratégias entre os próprios discentes e docentes para a democratização da construção do documento. Nota-se então que há um conflito, que ainda se assenta em uma concepção de modismo (burocrática, fragmentada, limitada, sem 
participação, autoritária, obscuro) do instrumento, inviabilizando propostas inovadoras e participativas.

Partindo da elucidação das bases legais e relacionais da construção do documento as categorias de análise expostas aqui diz respeito a necessidade de responder a questão: Como o PPP desenvolve os aspectos filosóficos em sua estrutura como documento fundamental para o direcionamento da Licenciatura?

\section{Concepções de campo, sujeitos do campo e Educação}

Ao analisar os aspectos postos no PPP uma das questões mais alarmante dizem respeito as concepções de campo, sujeitos e Educação postas dentro do documento. Assim, chamaram atenção no processo de análise, relacionados aos aspectos filosóficos o seguinte fragmento:

A carência de uma formação do magistério fundamentada nos preceitos e na filosofia da vida no campo repercute há tempos, na ação de subjugar o campo à cidade, ao seu ritmo, à sua cultura, à sua educação (Projeto Pedagógico do Curso de Educação do Campo -UFG - RC, 2014, p.08, grifos nossos).

A partir, principalmente da concepção de filosofia da vida no campo pode-se notar que a compreensão do mundo do campo liberta-se das bases excludentes que os negaram uma educação capaz de atuar de maneira transformadora no campo, e é proposta uma nova concepção que intermedia as relações, agora não excludente, dicotômicas e marginalizadoras, mas voltadas para os valores do campo e suas especificidades.

Tendo em vista que a prática filosófica tem como objeto os conflitos entre as diversas verdades que perpetuam a humanidade, buscando sistematiza-las a partir da atividade da razão. O PPP esse objeto é coloca um novo processo de entendimento das coisas, pessoas e contextos (problematizando verdades) a partir das centralidades que geram a vida no campo, conciliando as pontes, reconstruindo aspectos educacionais a partir da formação e protagonismo dos multipolos sujeitos do campo, seus modos de ser, sua ética e estética (Teixeira, 1971). Outro fragmento que subsidia essa discussão se coloca no seguinte discurso:

[...] uma formação oferecida pelo próprio curso, com intenção de familiarizar o docente e técnico recém-chegado nos princípios e na filosofia da Educação do Campo (Projeto Pedagógico do Curso de Educação do Campo -UFG - RC, 2014, p.115, grifos nossos).

Dessa forma, esses dois trechos, que trazem a filosofia do homem do campo e a filosofia da Educação do Campo, nos possibilitam inferir que suas bases filosóficas colocam com centralidade aspectos que dialogam com os percursos históricos da educação do campo e os modos de vida da população do campo, colocando como fundamental docentes que atuem 
nessa Licenciatura com postura que superem filosofias voltadas para a vida urbana. Fica evidente que a formação proposta pela LEdoC em questão está direcionada ao movimento contra-hegemônico, com princípios da existência do campesinato. Teixeira (1971, p.144) aponta a filosofia como "uma tentativa de "compreender" aspectos da vida e do mundo em um todo único", nessa perspectiva o PPP se consolida a partir de uma compreensão com bases na vida concreta do homem e da mulher do campo, compreendendo este como resultado de uma dinâmica relacional que historicamente o excluiu dos processos cidadania e direitos, mas que a partir da LEdoC essa compreensão admite-se sua existência como sujeitos de vida, com historicidade e concretude.

Entende-se a necessidade de se assegurar essas filosofias com base nos fluxos do campo, tendo em vista que uma concepção filosófica da classe dominante, que tende a permear os movimentos institucionais, não seria capaz de contemplar os modos de vida dos sujeitos do campo, que estão dentro de um movimento de luta e resistência (DEWEY, 2007). Teixeira (1971, p.147) com base em Dewey reafirma "A filosofia de um grupo que luta corajosamente para viver, não é a mesma de outro cujas facilidades transcorrem em uma tranquila e rica abundância".

Essa lógica de firmar apoio em uma filosofia que esteja atrelada com um percurso histórico, cultural e sociais concreto dos homens do campo, bem como do percurso da Educação do Campo (tendo em vista sua construção com base na classe trabalhadora do campo), está relacionada com a teoria chamada pragmática, elaborada por Dewey (2007). Tendo em vista que essa concepção se dá pela necessidade de se produzir um movimento de conhecimento dentro do processo de formação de Educadores do Campo articulado as formas de habitar, viver e desejar dos homens do campo, afim de desenvolver uma conexão entre o mundo do campo (suas tensionalidades e a necessidades) para construir processos formativos ligados com as reais necessidades desses sujeitos. Para que assim, seja empoderado Educadores capazes de intervir em realidade concretas dos indivíduos e do contexto do campo, ou seja, olhar para o mundo da experiência vivida por esses sujeitos e o conhecimento produzido nesse percurso, os potencializando para tratar experiências presente e futuros. Se rompe então o dualismo que separa os conteúdos produzidos sistematicamente nas instituições de ensino e o conhecimento produzido pela experiência, sendo nesse caso, a experiência do viver do campo e da luta pela Educação do Campo, o princípio que direciona e se associa ao conhecimento fixo e sistematizado, o dando um caráter dinâmico e pragmático (MOLINA, 2015). 
Dewey (2007) elucida um dualismo "entre conhecimento empírico e o racional mais elevado" (Ibidem, p.90), os povos do campo constituem muitas trilhas de conhecimento de forma empírica, a partir de suas necessidades relacionais com o ambiente. Porém, nos sistemas educacionais essas formas culturais de conhecer são inferiorizadas, desqualificados de qualquer potencial de formação. Se valorizando somente conhecimentos racionais postos como elevados, que se desenvolvem dentro de concepções urbanocentradas. Esses aspectos também buscam ser superada pela LEdoC, para que os futuros docentes se constituíam a partir da valorização das dinâmicas do campo, e que assim possa realizar um trabalho pautado na valorização cultura do campo. Nesse sentido mais um trecho nos auxilia a pensar nessa perspectiva:

Dentre os movimentos sociais buscaremos a formalização de parcerias, após contato inicial com: Movimento dos Sem Terra (MST), o Movimento Camponês Popular (MCP), Sindicato dos Trabalhadores Rurais de Catalão-GO, Movimento dos Atingidos por Barragem - Serra do Facão, Pastoral da Terra da Diocese de Ipameri, Liga Camponesa, Movimentos de Mulheres de Campo, dentre outros. A articulação do curso com esses setores organizados terá por finalidade a atenção às demandas da Educação do Campo a partir do olhar daqueles que vivem e se relacionam com o campo (Projeto Pedagógico do Curso de Educação do Campo -UFG - RC, 2014, p.12, grifos nossos).

Teixeira (1971) com base nos pressupostos postas acima reafirmam as questões, de compreender um processo formativo a partir das experiências reais, no caso, aqueles que vivem e se relacionam com o campo, tendo o modo educativo que está relacionado com os sujeitos que estão em pleno fluxo de vida, tornando a Universidade também um espaço de vida do campo. Em plena harmonia com essas questões o autor e Severino (2012) afirmam essa concepção deweyana, no estreitamente da relação entre educação e vida, a matérias postas nos sistemas de educação deve ser a vida, com suas fragilidades, contradições objetivando realizar progressos em torno dela. Nessa acepção "a aprendizagem resultante do processo educativo não tem outro fim, senão o de habilitar a viver melhor, senão o de melhor ajustar o homem às condições do seu meio" (Teixeira, 1971, p.59), assim, integra-se a vida concreta, as experiências fora do ambiente educativo, tendo os Movimentos Sociais do Campo suas mais puras relações com os contextos e tensionamentos da realidade do campo

Tratando-se do pressuposto dos Movimentos Sociais como agentes essenciais para se consolidar a LEdoC articulada com a necessidades dos sujeitos do campo, Boaventura de Souza Santos (2007) traz algumas reflexões interessantes. O Autor traz o conceito de razão indolente, essa razão se assenta sobre o dualismo presente também, de certa forma, nos escritos de Dewey (2007), onde se dá a criação de um abismo entre conhecimento racional hegemônico e conhecimentos empíricos tomados como irracionais, que acaba criando uma 
hierarquização, desqualificando todos outros conhecimentos alternativos (conhecimento dos povos do campo), consolidando uma monocultura do saber e do rigor, fortemente eurocêntrica. Dentro dessa dinâmica, os Movimentos Sociais possuem o potencial de romper esse abismo, de se tornarem um lugar para desenvolver novas ecologias para biodiversidade dos saberes,

[...] consiste na recuperação e valorização dos sistemas alternativos de produção, das organizações econômicas populares, das cooperativas operárias, das empresas autogestionadas, da economia solidária etc., que a ortodoxia produtivista capitalista ocultou ou desacreditou (Santos, 2007, p.36).

Ou seja, tomam como base a produção de conhecimento dos sujeitos que foram colonizados, mas conseguiram resistir a partir de produções sociais questionadores e tencionadoras da ordem vigente, concebendo ideais de futura a partir da realidade concreta e das estratégias de resistência ao capitalista para impor sua inexistência. Assim, as parcerias com os Movimentos Sociais tendem a fortalecer o surgimento de um novo paradigma emergente, a partir de uma concepção epistemológica do campo, e não mais para o campo, depois de um processo de luta e ocupação dos próprios Movimentos Sociais da Universidade. Outro trecho do PPP que também chama atenção é:

A escola rural e o docente que nela atua, se não tiverem a clareza da importância do homem do campo na sociedade, não conseguirá interagir com seus alunos e não conseguirá assegurar, de fato, uma educação do campo numa concepção transformadora e emancipadora (Projeto Pedagógico do Curso de Educação do Campo -UFG - RC, 2014, p.08, grifos nossos).

O uso do termo Escola Rural ainda mostra equívocos e contradições que permeiam o documento, tendo em vista que esse termo ainda remete a lógica da Educação Rural, sendo fixado um novo conceito que busca superar essa denominação que é Escola do Campo, pautado no Movimento de Educação do Campo (há 15 anos) (Molina, 2015). Nesse sentido podemos usar o conceito de falseamento ideológico, tendo em vista que a educação é um espaço propício para ocorrer esse processo, esse falseamento se dá pela dinâmica consciência da realidade social, fazendo com que a educação (apesar de inserir princípios de um determinado coletivo) acaba contribuindo para a legitimação de ideologias dominantes e padrões de uma sociedade autoconservadora, mesmo que inconscientes. Sendo necessário reforçar uma vigilância crítica sobre o conteúdo ideológico que cada termo pode carregar (Severino, 2012).

A questão do reconhecimento do homem do campo na sociedade, ou melhor, no processo de sociedade, já que essa sociedade vai se modificando com o passar do tempo, também se destaca. Deste modo, historicamente a concepção de homem do campo 
socialmente foi constituído com base em concepções preconceituosas, tendo em vista que a Educação Rural o concebe em um lugar de exclusão, reforçando a ideia de campo como lugar de atraso e cidade de avanço, colocando o homem que vive ali, também como atrasado. Assim, para as mudanças acontecerem é necessário que se conceba outro olhar para o homem do campo, o reconhecendo como sujeito fundamentais nas dinâmicas socais, com modos de vida legítimos. Assim, a LEdoC admite que nesses processos que ainda são presentes nos dias de hoje, esse projeto de formação não pode perpetuar essas concepções inferiorizantes de homem do campo, "precisa transformar-se no instrumento consciente, inteligente do aperfeiçoamento social” (Teixeira, 1971, p.101), a partir de concepções pautadas na justiça social, buscando assim novas projeções de presente e futuro.

Essa concepção de educação a partir de uma concepção transformadora $e$ emancipadora (postas no trecho acima) dialoga com os princípios da Educação do Campo, porém por vezes esses termos são postos sem bases fixas, de forma genérica, sem trazer reflexões sobre os seus reais sentidos dentro do contexto, como é visto no documento. Nesse sentido, Severino (2012), coloca que a educação pode sim superar seus modos reprodutivistas de relações de dominação, colocando em questão conteúdos ideológicos de resistência "contribuindo para relações político-sociais menos opressoras. Nessa medida torna-se uma prática transformadora" (Ibidem, p.75). Já a emancipação se dá pela passagem de relações colonialista (de não colocar o sujeito do campo como igual e sim como inferior; o silenciamento cultural desses sujeitos; expropriação de humanidade) para uma processo de autonomia solidária (rompe relações de silenciamento e de uma política de hegemonia; busca por uma filosofia do homem do campo; reconhecimento cultural, humanização), a educação se coloca na busca de contribuir na constituição de sujeitos mais empoderados sobre seu potencial de transformar as estruturas sociais a partir de seu lugar, lutando pela igualdade, mas respeitando as diferença e particularidades (Santos, 2007). Porém, esses conceitos precisam então vir com concepção menos desconexas no documento, para não deixar margem para ideologias dominantes e burguesas, fixando assim conceitos de maneira mais vinculadas com as pautas Movimentos Sociais do Campo, isso não acontecendo pode gerar a utilização desses conceitos como estratégias a partir de uma ótica liberal ou neoliberal, não contemplando a classe trabalhadora do campo.

Por esse ângulo algumas questões nos chamam atenção, é posto que a Educação do Campo está estreitamente vinculada com um projeto de desenvolvimento social com bases na classe trabalhadora do campo, sendo assim, está articulada com um projeto popular de Reforma Agrária e agricultura familiar camponesa, com a necessidade se se superar modelos 
de produção capitalista (modelo de agricultura do Agronegócio). Nesse sentido a LEdoC se institui com a função de desenvolver processos formativos capazes de gerar consciência de classe, estreitamente vinculados com a classe trabalhadora, estabelecendo assim a formação de intelectuais comprometido com a luta e resistência dos Movimentos Sociais do campo, tendo em vista o tensionamento do campo pela acumulação de capital através do Agronegócio (Caldart, 2008). Assim, “o sentido da expansão da oferta das Licenciaturas em Educação do Campo não pode ser compreendido em separado dos intensos conflitos em torno do modelo de desenvolvimento hegemônico no campo na atualidade" (Molina, 2015, p.75). Evidencia-se questões são postas dentro do PPP, porém com pouco notoriedade, caracterizando assim uma negligência em fixar fatos que afirmam e marcam uma luta de classes que caracterizam a Educação do Campo, e assim não materializando de maneira concreta concepções que promovam uma consciência de classe como um aspecto fundamental no processo educativo da LEdoC em questão.

\section{Concepções de Educadores do Campo}

Aqui será posto reflexões sobre as concepções de Educadores do Campo no LEdoC, tendo em vista que se concebe Educadores do Campo como os próprios docentes das licenciaturas e os discentes em formação.

O PPP expõe que os sujeitos (docentes e técnicos) que atuarão na Licenciatura devem compreender a bases do curso que estão apoiadas no Programa de Formação Docente para a Problemática do Campo. Assim, trazemos um trecho já apresentado no subtópico anterior para realizarmos mais uma discussão:

\footnotetext{
O programa prevê que o docente ao ingressar no curso, possa conhecer melhor o projeto de formação do qual fará parte. Trata-se de uma formação oferecida pelo próprio curso, com intenção de familiarizar o docente e técnico recém-chegado nos princípios e na filosofia da Educação do Campo (Projeto Pedagógico do Curso de Educação do Campo -UFG - RC, 2014, p.115, grifos nossos).
}

Mostra-se a intencionalidade em desenvolver um curso capaz de gerar a partir de um processo formativo sujeitos que atuarão na LEdoC com bases na Filosofia da Educação do Campo, então é posto a necessidade de os próprios sujeitos que atuaram como formadores na Licenciatura incorporem essa perspectiva e proposta do curso. Algo que dentro da dinâmica do curso se coloca como fundamental, devido à complexidade em superar lógica urbanocentradas no processo de educação. Nesse sentido podemos entender que o Programa em questão tem base em uma formação que tende a desenvolver reflexões filosóficas acerca dos processos sociais da Educação do Campo, bem como seus movimentos de luta, seus modos de vida e produção. Assim, a filosofia tomaria o papel de expor valores, questiona-los, 
a partir de um processo crítico sobre o que permeou a marginalização dos povos do campo, e quais são o papel dos docentes e técnicos no processo de produção de um movimento educativo mais justo e que parte dos próprios sujeitos concretos (Severino, 2012). Se mostrando nesses sentido uma estratégia válida, se operada da maneira proposta.

Os trechos abaixo nos chamaram a atenção:

[...]o intercâmbio e a socialização de atividades multidisciplinares no processo de formação. (Projeto Pedagógico do Curso de Educação do Campo -UFG - RC, 2014, p.4, grifos nossos).

[...] o curso de Licenciatura em Educação do Campo privilegiará a interdisciplinaridade como forma de trabalho no ensino, na pesquisa e na extensão (Projeto Pedagógico do Curso de Educação do Campo -UFG - RC, 2014, p.39, grifos nossos).

A LEdoC coloca a multidisciplinaridade e interdisciplinaridade como princípios fundamentais para a formação do Educador do Campo, essa concepção rompe com uma lógica reducionista volta para o positivismo, em uma perspectiva fragmentada de educação. Severino (2012) afirma que a educação é um processo complexo que está inserido em um processo de integração dos fenômenos humanos a nível de historicidade, tendo então que se firmar em um processo multidisciplinar, pois seria impossível sua organização pautada em uma única disciplina, sendo a educação um campo epistemológico que advém de diversas áreas de conhecimento. E para além disso, a soma de disciplinas não seria suficiente, é necessária a consolidação da interdisciplinaridade, que não é a fusão ou perda de identidade das disciplinas, mas a construção a partir de diálogos, voltada para um olhar coletivo, formando assim uma ponte "entre os vários campos de saber na abordagem do objeto/educação" (Ibidem, p.115). Assim, concebe essa necessidade dentro da formação dos educadores, para que esses consigam consolidar pontes entre saberes para direciona-los na compreensão e transformação das questões que envolvem os sujeitos do campo no âmbito da pesquisa, extensão e ensino. Aqui o regime de alternância (tempo universidade - tempo comunidade) também tem papel essencial, pois esse intercâmbio de saberes tem como fonte os saberes e experiências vivenciados nas comunidades, os saberes populares (Molina, 2015; Caldart, 2008).

É importante, se formar um professor que dialogue com a cultura do campo $\mathrm{e}$ perpasse pela própria experiência com esta realidade, com a práxis social deste docente que compreenda e interaja com a realidade do campo sem desmerecế-lo (Projeto Pedagógico do Curso de Educação do Campo -UFG - RC, 2014, p.33, grifos nossos). 
O trecho acima nos auxilia a fazer algumas reflexões. Há a necessidade de se formar sujeitos que superem uma formação apenas técnica, voltada para a eficiência do seu trabalho em uma perspectiva mecanicista, é necessário que se fortaleça um processo de "afeto" e "empatia" com a cultura do campo e com seus movimentos. Para que assim, seja possível gerar uma práxis social voltada para a compreensão dos tensionamentos complexos que rodeiam o campo, e acima de tudo compreender "que a vida envolve um pouco pelo seu esforço próprio de melhor agir [como futuro educador], a fim de concorrer para o enriquecimento e o processo da existência humana [no campo]" (Teixeira, 1971, p.104). Com esses elementos de cultura vai ser possível renovar a humanidade nos processos educativos do povo do campo, o docente então "tem que usar a legenda do filósofo: "Nada que é humano me é estranho"' (Ibidem, p.149), e assim se permitir transitar sobre os aspetos que envolvem o campo brasileiro de uma práxis educacional concreta dos educadores (Severino, 2012).

Outro aspecto no trecho acima é a necessidade de se valorizar a própria experiência futuro docente com a realidade do campo, afirmando a discussão no subtópico anterior, de valorização da experiência para construir processos educativos que dialoguem com a vida dos sujeitos (nas experiências de todos os sujeitos, dos que vivem no campo, dos Movimentos Sociais e dos próprios futuros educadores são do campo ou não), que gerem sentido em uma perspectiva pragmática, levando em conta que tomar as experiências como instrumentos que fortalecem a tomada de decisões sobre os problemas futuros (Teixeira, 1971; Dewey, 2007). Isso se afirmar na LEdoC pelo fato da sua própria lógica que é pautada no regime de alternância, que tem por finalidade de além de possibilitar o acesso à universidade de sujeitos do campo sem que esses precisem se mudar de seus territórios, desencadear um processo educativo com articulação entre realidade especifica e educação, sendo o tempo comunidade um espaço de capitalização de experiência articuladas com os processos do tempo universidade (Molina, 2015).

Esse movimento se faz necessário para que os futuros Educadores do Campo tenham a capacidade de realizar movimentos de transformação nas escolas e comunidades do campo. Assim, se faz necessário não apenas instrui-los como educadores com o conhecimento técnico, mas com processos que os levem a uma plena formação humana, objetivando que sejam críticos sobre as historicidades e conjunturas do campo, reconhecendo os valores da população camponesa dentro das estruturas de contradições. Outro trecho nos chama atenção:

A forma como os direitos destes sujeitos é vista pelo professor, interfere em como este aluno se reconhece como sujeito destes direitos. [...]. Para que este projeto de educação aconteça é imprescindível que, o professor conheça estes direitos e, seja capaz de organizar um projeto educativo coerente e participativo (Projeto 
Pedagógico do Curso de Educação do Campo -UFG - RC, 2014, p.34, grifos nossos).

Olhar para os sujeitos do campo como agentes de direito, para que dentro da práxis educativa coerente e participativa isso possa fortalecer o reconhecimento e empoderamento desses como sujeitos direitos. Sujeitos que tem o direito de uma educação a partir de sua realidade, sua filosofia de vida, rompendo os dualismos de classe que ainda assolam as ideologias que perpassam a Universidade. A partir desse reconhecimento busca-se uma intencionalidade em prol da democracia, que traga igualdade de oportunidade, voltado para o fim da desigualdade econômica, desencadeando a felicidade como princípio fundamental para a vida humana. Porém, essas ideias precisam alicerçar dentro de princípios de equidade, compreendendo que a Educação precisa dialogar com as necessidades sociais dos sujeitos do campo, os reconhecendo a partir de direitos para sua necessidade, e não como sujeitos de direito a partir de uma concepção generalista, acreditando assim que isso levará a universalização de uma educação pública, justa e capaz de transformar as realidades especificas e com isso as realidades globais (Teixeira, 1971; Dewey, 2008). Assim, se concebem aqui um processo formativo do educador que

[...] não pode ser equiparado a nenhum técnico, no sentido usual e restrito da palavra. Ao lado da informação e da técnica, deve possuir uma clara filosofia da vida humano [no campo], e uma visão delicada e aguda da natureza do homem [do campo] (Teixeira, 1971, p.150, com alterações)

\section{CONSIDERAÇÕES FINAIS}

Os aspectos filosóficos que repassam o PPP da LEdoC da UFG/RC têm como base questões relacionadas a uma proposta que dialoga com o processo de construção do Movimento de Educação do Campo, ou seja, alicerça-se dentro de uma concepção de homem, mundo, educação e educadores que se preocupa em produzir uma filosofia da vida do campo e filosofia da Educação do Campo, no reconhecimento dos sujeitos do campo como protagonistas nessa Licenciatura, e com a necessidade de compreender que essa Educação deve ser do e no campo e não para o campo. Isso se reflete nas estratégias em propor uma vinculação com os Movimentos Sociais, concebendo uma importância a experiência e a vinculação com a vida concreta, a interdisciplinaridade, a valorização do conhecimento e construção de uma biodiversidade de conhecimento voltado para a cultura do campo, na importância dada em romper lógicas urbanocêntricas, olhar para o homem do campo e seus 
conflitos sociais, admitindo sua importância na estrutura social e o reconhecimento como sujeitos de direito.

Porém, apesar dessas questões notamos que os aspectos filosóficos no PPP avaliado ainda são implícitos e superficiais, sendo necessário maiores aprofundamentos sobre suas bases e fundamentos, pois essa falta de aprofundamento de uma filosofia intituinte e que provoque uma ruptura a processos de exclusão dominantes são fundamentais para sua consolidação. Além disso, seria essencial que o PPP trouxesse de maneira mais explicita questões sobre consciência de classe, reforma agrária, projeto de desenvolvimento societário (conflitos entre modos de produção), os processos de luta pela terra e por direitos sociais, bem como a materialização de conceitos como transformação e emancipação de maneira mais elabora e conexa com as tensionalidades que oprimem o campo brasileiro, trazendo as dimensões da LEdoC na sociedade. Tendo em vista que as ausências de aprofundamento podem dar margens para o uso desse PPP em uma perspectiva de falseamento ideológico, necessitando assim de maior vigilância crítica. Assim, deve-se refletir sobre a necessidade de materializar questões mais fortemente intituintes, relacionados com as pautas em uma perspectiva mais macrossocial, levando em consideração que a LEdoC surge com a função de desestabilizar relações de desigualdade, exclusão e dominação, com um processo emancipatório voltada para a classe trabalhadora do campo. Firmando assim que a educação posta na Licenciatura é uma educação que "não é sinônimo de ensino e sim uma intervenção mais abrangente, alcançando outros espaços da vida da sociedade" (Severino, 2012, p.141).

Veiga (2007) aponta que o que propicia uma perspectiva ao PPP é sua intencionalidade, sendo assim, as intenções postas no PPP em questão conseguem erguer uma articulação e reflexão sobre a LEdoC em relação ao homem, ao mundo e a educação. Mesmo que essas dimensões ainda não contemplem de maneira totalitária a perspectiva da Educação do Campo o documento traz possibilidade de ações práticas que criam janelas para movimentos instituintes. Já na perspectiva da inovação, que prevê um movimento de ruptura com as formas de poder, e acima de tudo valoriza ao processo de construção do documento (coletivo, participativo, que busca reduzir distância entre o discurso e a prática), o mesmo apresenta um déficit, já que essa inovação tem que se dá a partir de fluxos coletivos e esse aspecto é ainda pouco visível no PPP, o que acaba o fixando no modismo (instrumento fixo, de normas dadas, com no máximo reformas). Consideramos então, que há janelas instituintes que revê as questões instituídas, para supera-las e desenvolver um novo processo formativo nas especificidades do campo, voltado para a transição e ruptura, porém ainda há um modismo encarnado. Assim, a declaração de boas intenções talvez não seja capaz de 
desencadear mudanças efetivas nas práticas e dinâmicas institucionais. Sinalizando assim a necessidade de um olhar mais atento sobre essas questões.

O curso de LEdoC na UFG/ RC está em pleno período embrionário, ou seja, está em processo de construção de identidade, dando luz a diversas questões que devem ser trabalhadas para a sua melhoria, uma delas é o aprofundamento das questões que envolvem a Filosofia da Educação do Campo, enfatizando princípios gerais da formação humana e pedagógica presentes na formação de professores e, principalmente, sempre colocando em pauta as caraterísticas especificas da formação de Educadores do Campo, que prima pela formação humana, crítica e política, ou seja, pessoas que busquem e promovam direitos, deveres e saberes dos povos do campo. Para que futuramente possa construir um documento inovador, que dê o norte aos caminhos da Licenciatura.

Esse trabalho se propôs a produzir reflexões acerca dos aspectos filosóficos no PPP em questão, porém é ainda uma reflexão que precisa de maiores aprofundamentos, sendo posto aqui somente algumas questões mais alarmantes da análise, abrindo caminho para novas pesquisas de análise documental, e além disso, pesquisas que investiguem como os PPP estão articuladas nas práticas da LEdoC. Sempre buscando o fortalecimento e potencialização da Licenciatura sem perder seus princípios originários, a partir dos pressupostos dos Movimento de Educação do Campo, e auxiliar sua efetivação enquanto movimento para contribuir no fortalecimento e na transformação da vida dos sujeitos do campo brasileiro.

\section{REFERÊNCIAS}

BARDIN, L. Análise de Conteúdo. São Paulo: Edições 70, 2011.

BRASIL, Ministério da Educação. Edital de seleção $n^{\circ}$ 2012. SESU/SETEC/SECADI/MEC. Brasília, Distrito Federal, 2012

SANTOS, Boaventura de S. Renovar a teoria crítica e reinventar a emancipação social (tradução Mouzar Benedito). SãoPaulo: Boitempo, 2007.

CALDART, Roseli Salete. Sobre educação do campo. In: SANTOS, C. A. dos (Org.). Educação do campo: campo - políticas públicas - educação. (NEAD Especial: 10). Brasília: INCRA; MDA, 2008. p. 67-97

CARVALHO, Viviane Batista. Relacionando a Filosofia a Elaboração do Projeto PolíticoPedagógico nos Centros de Educação Infantil. Anais... IX Congresso Nacional de Educação e III Encontro Sul Brasileiro de Psicopedagogia. PUC - PR, 2009.

CAMPOS, Camila Aparecida. de. Procampo em Catalão: da Interdisciplinaridade que temos à que queremos. Enciclopédia Biosfera. Goiânia, v.11, n.20, 2015. 
CALAZANS, Maria Julieta Costa; CASTRO, Leonardo Freitas Moraes; SILVA, Helio Ricardo. Questões e Contradições da Educação Rural no Brasil. In.: WERTHEIN, J; BORDENAVE, J. D. (org.). Educação Rural no Terceiro Mundo: Experiências e Novas Alternativas. Rio de Janeiro: Paz e Terra,1981, p. 161-198.

DEWEY, John. Democracia e educação: capítulos essenciais. São Paulo: Ática, 2007. 136 p.

FAGUNDES, Mauricio César Vitória. Universidade e Projeto político-pedagógico: diálogos possíveis fomentando formações emancipatórias. Tese (Doutorado em Educação). Universidade do Vale do Rio dos Sinos, 2009.

GODOY, Arilda Schmidt. Pesquisa Qualitativa - Tipos e fundamentos. Revista de Administração de Empresas, São Paulo, v. 35, n.3, p, 20-29 Mai./Jun. 1995.

MOLINA, Mônica Castanha. Expansão das licenciaturas em Educação do Campo: desafios e potencialidades. Educar em Revista. Curitiba, Brasil, n. 55, p. 145-166, jan./mar. 2015.

Projeto Pedagógico do Curso de Licenciatura em Educação do Campo da Universidade Federal do Goiás - Regional Catalão, 2014.

SEVERINO, Antônio José. Educação, sujeito e história. 3. ed. São Paulo: Olho d’Água, 2012.

SILVA, Heloiza Henê Marinho da. Subsídios para a Elaboração do Projeto PolíticoPedagógico. In.: ALMEIDA, M. D. de. (Org.). Projeto Político-Pedagógico. 2. ed. - Natal, RN: EDUFRN - Editora da UFRN, 2004. 46 p.

TEIXEIRA, Anísio. Pequena introdução à filosofia da educação: escola progressiva ou a transformação da escola. São Paulo: Nacional, 1971.

VEIGA, Ilma Passos Alencastro. Educação básica: Projeto político-pedagógico. 2 ed. Campinas, SP: Papirus, 2007.

Escola: espaço do projeto político-pedagógico. 4. ed. Campinas: Papirus,1998. 